\title{
The implications of Iran sanctions on civilian mental health and quality of life
}

\author{
Mohammad Tahan ${ }^{1}$ \\ 1.Young Researchers and Elite Club, Birjand Branch, Islamic Azad University, Birjand, Iran. \\ Email: t.mohammad2@gmail.com, sa95tahanmohammad@iaubir.ac.ir \\ Tel: +989120252104 \\ Orcid ID: 0000-0003-2175-4584
}

\begin{abstract}
In order to synchronize foreign policies of governments, firm actions in the form of economic sanctions have long been employed by western countries. Those countries that tend to have independent views and policies are made to undergo economic adversity to fall in line. But the hardest hit by these coercive actions are the ordinary citizens who have to endure immense difficulty with social and economic issues not to mention the human rights violations. This paper provides a review regarding the effect of economic sanctions on mental health and quality of life of Iranian citizens based on data available from Iran post-sanctions. From 2012 stronger sanctions have been implemented on Iran as its nuclear program failed to draw faith in terms of its peaceful execution. Evidence have pointed out that economic sanctions imposed by western countries have a detrimental and destructive effect on the health of individual Iranians and they violated some basic human rights.
\end{abstract}

Key word: Iran; sanctions; mental health; quality of life 


\section{Introduction}

Trade sanctions are tough foreign policy measures that governmental bodies impose by curbing economic ties on another country with the intent to pressurize them to accede. These economic sanctions are meant to avert war or other violent means to gain submission. Economic relations encompass trade and financial tie-ups. This involves disruption of the economic networks, either full or partial, including air, communications, postal, rail, radio, sea, and telegraphic sectors, including the dwindling international relations. UN members must discuss these aspects with the Council. ${ }^{1}$ In an attempt to make one country match up or reconsider conflicting policy decisions, another country might compel them through these means, for instance, to restrain nuclear enrichment. Post-Cold War, sanctions are meant as another less violent yet deadly substitute to war. Although these sanctions are levied on governments to modify policies the most affected are the common people of the target country. Mortality and suffering are a result of imposed sanctions and humanitarian efforts itself cannot pacify those who belong to the lower strata. Thus the influence of sanctions on the macroeconomic and political aspect has always been a contentious issue. As Iran's nuclear activities had come under a scanner from 2003, for its unclear objectives therefore its enrichment related and reprocessing activities and research were asked to be stalled. But considering the developments from Iran's end seemed unsatisfactory by the IAEA in 2006, case of Iran was brought to UN Security Council which also did not find the trust building attempt up to the mark. Council's sanction processing related to its nuclear activities was questioned by Iran in 2007. No economic sanctions were implemented apart from military and nuclear industry. But some countries decided to go ahead with coercive diplomacy and imposed economic sanctions in 2012. ${ }^{1}$ Post-sanctions Iran's revenues plummeted, currency devaluated, with added surge in inflation and unemployment. These aspects fiddled with the civilians' right basic requirements of standard life including nutritious food, healthcare and medicine. ${ }^{1}$ Apart from lower medicine supply there are many factors which dwindles health and health services; namely water, sanitation, infrastructure, electrical supply, ambulance services and hospital set up. Diminished civilian health is also found to be as a result of limited access to imported raw materials and machines for production purposes. Effectiveness of humanitarian immunity is more theory than practicable to sustain health and health services. Other than weakened physical and medical infrastructure sanction imposed restricted state cash flow impacts maintenance and administrative costs roil the provision of better services and sub-optimal reflex to medical emergencies. Demotivation creeps in people with the deteriorating quantity and quality of health services who might consider abandoning these services. Embargo wrecks havoc on employment and livelihoods forcing civilians to opt for alternative social and economic activities. This paper attempts to investigate the detrimental effect of western sanctions to Iran its impact on health, mental health and quality of life. ${ }^{5}$ This paper discussed about economic sanctions and human rights violations that it incurs. Economic sanctions and the 
consequences on health, medical care and food security in Iran, its repercussions on mental health and quality of life of the inhabitants are presented.

\section{Hostile sanctions of the US government and European countries:}

Donald Trump seeks to renegotiate the landmark nuclear accord reached with Iran and, as part of that effort, reinstated sanctions against Iran in 2017-18. Despite the considerable burden of these sanctions to Iran, the country's leaders have not yielded to President Trump's threats. ${ }^{6}$ To encourage Iranian President Hassan Rouhani to persist in complying with the accord, European officials have begun working with their counterparts in Russia and China to develop strategies to allow Tehran to continue to profit from its oil sales. This outreach comes as the European Union has struggled to circumvent the U.S. financial system in order to resist President Trump's efforts and protect its companies in Iran in a feasible and legal manner. ${ }^{7}$

\section{Sliding towards a deep recession:}

In recent years, Iran's economy greatly suffered from the global community's sanctions caused by its ongoing nuclear initiatives. Sometime in 2015, President Hassan Rouhani made a pact with the United States and five other superpower nations to minimise its nuclear activities in exchange for the reduction of imposed sanctions in Iran. $^{8}$

\section{Impact of economic sanctions on Iranian}

\section{Drugs and raw materials:}

Essentially, the supposedly sanctions directed to Iran's existing nuclear activities have brought detrimental effects on the health of common Iranians. This impacts their limited access to medicines and declining health services. It has left around 6 million local patients seeking various treatments for their long list of sick people. ${ }^{9}$ As a result of the imposed sanctions, Iran's pharma sector cannot sustain its domestic needs, causing some difficulties in producing its own generic drugs and importing low-quality medicines and other raw materials abroad without ensuring their potency. In Setayesh and Tim (2016) study, it noted that the increasing economic sanctions put a major toll on Iran's medical need's shortages that severely affects the living conditions of Iranian patients and their human right to good health. ${ }^{9}$

Impact of sanctions and psychological warfare on the mental health and quality of life:

Countries that have imposed financial sanctions against Iran have interfered with Iranians' right to a healthy life. In 2018, Kokabisaghi assessed the effects of economic sanctions on Iranians' right to health by using a human rights impact assessment tool in his systematic review. The International community of nations is well able to predict the humanitarian effects of sanctions and could have chosen any one of the 
many available and necessary means to prevent such humanitarian distress. Furthermore, Iran should have used any mandatory means to protect people from the adverse effects of sanctions. ${ }^{10}$ Now, they must focus on alleviation of the negative impact of economical sanctions, after the fact. Nevertheless, some of the effects like disability and death cannot be compensated. In the future, when sanctions are considered, decision makers should establish an international convention to mitigate such impacts on targeted countries' populations. ${ }^{10}$

\section{Economic Sanctions and Human Rights:}

Post- Cold War, with the advent of expanded global market major super powers do not opt for a run in by the military. To get nations to comply in an attempt to achieve peace and block civil or overseas war the United Nations and other countries prefer imposing economic sanctions rather than military intervention. The consequence of this action is obstacle economic development of sanctioned country and impact welfare of the entire population. Countries have to face revoking of political relations, economic, and communications are some of the coercive foreign policy measures in the form of sanctions. The countries are targeted by limiting import or export trade activities, freezing of bank-account, travel restrictions, elevating tariff rates and other pressures tactics that relegates the economy immensely. ${ }^{11}$

Compared to the irreversible repercussions of a war, economic sanctions seem to be a milder option. But the very intention to preserve the human rights the target country is expected to uphold gets violated once sanctions are imposed. Considering the civilians residing in the sanction-imposed areas suffer drastic impact on their health and human rights. Human rights violations that inevitably follow imposing economic sanctions include rights to: life, liberty and security of person, freedom of opinion and expression, adequate food, the highest possible standard of physical and mental health, provision of medical assistance and health care, adequate clothing and housing, adequate environmental conditions, adequate standard of living that can ensure health and well-being, education, work and to just and favourable conditions of work, social security, and the right to participate in government. ${ }^{12}$

The basic fabric International human rights which pledged to safeguard and honour basic human needs are shredded once a country is subjected to sanctions dissolving the very the spirit of the International Covenant. Furthermore to political and civil rights, the 1948 Universal Declaration of Human Rights refers to an individual's right to better living standards and seek optimal health and wellbeing; inclusive of food security and medical care. ${ }^{13}$ Lately, in 1976, the International Covenant on Economic, Social, and Cultural Rights extended support towards achieving best standard of physical and mental health; and asked for all countries participation in attaining the prevention, treatment, and disease control and proper delivery of medical care. ${ }^{14} \mathrm{~A}$ balance between maintaining law and human right protection is always expected by international law. In times bereft of war it is mandatory to maintain 
provision of civilians and medical supplies, chances of contagious diseases and epidemics could be deflected by giving adequate access to medical centers, hospitals, and other public health infrastructure. These parameters are acceptable even at times of economic sanctions and war. ${ }^{14}$

Humanitarian efforts are most of the time excluded from the range of sanctions. But how can this be possible if foreign currency is made unavailable, bank accounts are not allowed to function or cross border transactions are not allowed. Stringency in terms of trade, export licenses retrieval or transportation surveillance, makes access to food and medicine tough. Clinically, this refers to promoting the highest standards of medical care for individual patients. Physicians must concentrate on their expertise and duty and try to diffuse any possible tension emanating from government policy decisions. Health is an amalgamation of mental, physical and social well-being there is a fundamental association between conserving human rights and promotion of health are correlated for human well-being. Higher socioeconomic status and better health status are often interlinked. ${ }^{14}$

On a general front, several countries worldwide are undergoing enormous psychosocial stresses and issues; this has affected the psychological well-being and the lack of mental realm of primary healthcare requisites. Existence of psychological well-being or lack of a mental illness provides endurance to everyday stress, and active role within the social precincts of the community where the individual resides. Mental and behavioral disorders are major disease forms. The total estimated rise in mental and neurological disorders from 1990 to 2020 is expected to be $15 \%$. Mental disorders are one of the leading causes of disability and early mortality. Previously retrospective clinical data records and epidemiological study summed up statistically to evaluate the preponderance of total mental disorder. Presently advanced screening questionnaires and standard clinical interviews, are employed for more accuracy in the estimation. According to the WHO 2001 mental and behavioral disorders are the most frequent with $25 \%$ affected during their life. The 2013 NSDUH data, showed the 12-month prevalence of mental illness was $18.5 \%$ in those $\geq 18$ years. ${ }^{15}$

\section{Iran's mental health facilities:}

Even though spacious mentally ill shelters existed in Iran since 1940 they were not in workable conditions. The transition came about in the 1950s and 60s when psychiatric hospitals and departments came about in the 1950s and improved services were rendered to psychiatric patients. 1983 saw the establishment of improved primary health-care system but after Iran-Iraq war concerns mental health problems shot up. In 1986, although there was increased incidence of mental disorders it had low capacity to respond, mostly in rural areas. To tackle this issue the first National Programme on Mental Health was developed in Iran to cater to the underprivileged, deprived, and at-risk populations and provide access to primary mental health-care facilities. It was pledged that a mental health was made available to all 
Iranians by the year 2000 the primary health-care system was employed as the primary delivery platform for its execution. Four categories of mental disorders were selected and were asked to see the general physicians and follow up these patients based on the instructions. After 15 years mental health facilities were functioning in rural health centres in 2005. The programme saw increased implementation and awareness but this was not matched with the outcomes, physician skills, supply of psychiatric medications, and outcomes of the treatment. Industrialization and urbanization, added up the number of cases but mental health programme was unprepared to take it up. ${ }^{16}$

\section{Iran embargoes and mental health:}

Based on the present state of events patients tend to be anxious about the future. This feature culminates into multiple forms of anxiety disorder in which these individuals dwell on feelings of extreme anxiety and fear. Elevated personal, social and economic liability precipitate to anxiety disorders. ${ }^{17}$ It is common for anxiety disorders to be associated with other psychological conditions especially major depressive disorder. ${ }^{18}$

Epidemiologic studies have indicated that a major proportion of Iranians suffer from mental disorders and psychological conditions. Prevalence of mental disorders is only next to that of unintentional injuries with respect to preponderance of disease in Iran, which is almost $16 \%$ of the overall burden of diseases. ${ }^{19}$ In Iran, psychological disorders estimate $10.8 \%$ of the total population, out of which anxiety disorders is frequent with $8.4 \% .{ }^{20}$ It is the aftermath of low socioeconomic status, illiteracy; low level of education, unemployment translates into people with inferior socioeconomic status and poorer health indices. ${ }^{21}$

In accordance to a survey performed in $1999,21 \%$ of the Iranian population $\geq 15$ years suffered from mental disorders. The preponderance of mental disorders as per the prevalence of mental disorders GHQ28 ranged from $21 \%$ to $34.2 \%$. Out of every 4 citizen at least one suffered from a mental disorder. The second survey conducted in (2001), showed a frequency of $17.0 \%$ as assessed by SADS. in the third nationwide survey of mental disorders, While GHQ-28 and the CIDI enumeration in 2011 yielded a $22.7 \%$ presence of mental health. These variable outcomes were due to statistical population, scoring methods and dynamics of social, economic, and political situation of Iran. An upswing of mental illness is evident from the Iranian studies $21 \%$ in 1999 to $23.44 \%$ in $2017 .^{22}$

The outcomes of a 12 months national MHS conducted by employing Composite International Diagnostic Interview CIDI diagnostic tool in 2011 revealed anxiety disorders to be $15.6 \%$. All types of anxiety disorders exhibited increased prevalence of anxiety disorders in females (19.4\%) relative to males $(12 \%)$. As per the study generalized anxiety disorder (5.2\%), obsessive-compulsive disorder (5.1\%) and social phobia (3.2\%) were the frequent forms of anxiety disorders. ${ }^{23}$ 
Female sex has a higher propensity towards anxiety related disorders. This could be attributable to environmental factors, genetics ${ }^{24}$, female sex hormones and related cycles. ${ }^{25,26}$ Greater fear response and penchant for safety is prominent in females as opposed to males; the difference is reflected through imaging studies in the presence of anterior cingulated cortex in females. ${ }^{27}$ Poor health is directly proportional to socioeconomic factors like inadequate education, low income, stress, unhealthy lifestyle and occupational conditions. ${ }^{28}$ Illiteracy and poor education underrate people. ${ }^{29}$ apart from this limited accessibility to mental health services, social support and health care services are also expected. ${ }^{30,31}$ Poverty, unemployment and incarceration are often linked to being uneducated. ${ }^{31}$ Poor education does not directly correlate to mental health problems if social solidarity is at one's disposal. ${ }^{32}$ It is very clear that unemployment accelerates the development and aggravation of psychiatric disorders. ${ }^{33,34}$ Negative impact of psychosocial and work functioning, increased fatigue and sleep disturbance, limited physical health, suicide attempts, global cognitive impairment and social disability are consequences of generalized anxiety disorder. ${ }^{35}$

\section{Mental health in children and adolescent:}

Anxiety disorders incidence in varied based on different regions of Iran. In children the preponderance of anxiety disorder in pre-puberty days are $2.6 \%$ to $41.2 \%$, Zarafshan et al presented a grimmer picture of $6.8 \%$ to $85 \%$ of Iranian children and adolescents. ${ }^{36}$ Bandar Abbes city was leading in the frequency of anxiety disorders, but needs further evaluation. Separation anxiety disorder frequency ranged between $0.7 \%$ to $15.7 \%$ among Iranian children and adolescents. Generalized anxiety disorder ranged from $0.54 \%$ to $12.8 \%$, with an exception in Abhor where generalized anxiety disorder was $20 \%$. OCD ranged from $1 \%$ to $11.9 \%$ among Iranian children and adolescents. Incidence of social phobia was as high as, $8 \%$ to $23.5 \%$ among Iranian children and adolescents. Overall, this high prevalence of social phobia among Iranian children and adolescents needs to be considered. Specific phobia was found to be $1.6 \%$ and $3 \%$. The frequency rate of panic disorder was $1 \%$ and $1.2 \%$ for agoraphobia, which were slightly higher than two studies reporting the. Across all the reports, anxiety disorders were almost doubled in females relative to males. ${ }^{36}$

\section{Quality of Life in Iran:}

Although it is not easy to define quality of life, medically, Qol has several different nuances and meanings and includes psychological, social and emotional, functional capacities, life satisfaction, and social support parameters. In the absence of a definitive definition even all non-medical aspects of disease are enlisted under the term of Qol. ${ }^{37}$ A good quality of life is synonym to the state of being in control, autonomy and ability to choose; a pleasant self-image; a sense of belonging; always hopeful and positive, 
participating in sensible and fun tasks. On the contrary, severe mentally unhealthy individuals are mostly in the state of ill-being. While those with mental issues execute a poor quality of life, as they live with mental health difficulties, like feelings of suffering; uncontrolled behavior, choice and autonomy; poor self-esteem and confidence; a sense of not being part of society; diminished activity; and a sense of hopelessness and dejected with life in general. ${ }^{38}$

Subjective well-being is associated with actual affective state, can oscillate swiftly. Social participation tends to disrupt easily, largely it may be a gradual process. Environmental living conditions either material or social can also interrupt the functioning. As the depression progresses individuals' subjective well-being diminishes although apparently the person might be continuing with day to day social activity. Even if functioning is hampered in some cases, material living conditions and social support might remain unchanged. While in some instances, once social participation has dwindled due to extended period of the disease, while environmental assets, both material and social, have diminished, a patient might gain psychological well-being rather quickly, but which is not on par with social roles functioning. Even if at all environmental living conditions were to be gained. ${ }^{39}$

Complex time issue may occur if the expectations are not according to what is at hand. Qol is high if the disparity between the expectations and achievements are narrow. In this perspective, for each individual, the complexity raises with regards to ones priority a better life at present or better standards that might occur later. The disparity must be lower. Quick acting psychotropic substances among multiple escapes like tranquilizers or alcohol can provide short term relief from the constant mental conflict the individual might be experiencing. Therefore it may naturally transition into substance abuse which might lead to a widening of this gap, and this dependence indicates lowered psychological well-being, waning of social presence, and collapsing living condition both environmental as well as societal. In the rampant administration of first generation narcoleptics, patients had to choose between two options: the use of narcoleptics reduced the recurrence frequency, although serious side effects ensued and patients had to weigh the pros and cons between bearing the costs and side effects or endure these for future good. The scenario could be changed by the use of novel atypical antipsychotics. ${ }^{36}$

Geriatric people do not enjoy complete mental health condition. Measures have to be taken by family members, society, and government alike in keeping them occupied, old age pension scheme or elderly self-help set will ensure them to lead a contentful life. ${ }^{39}$ Evidence have accepted the fact that not having financial independence have detrimental effects on the mental and physical health of geriatric people. ${ }^{39}$

Immediate attention with regards to Iran's fragile health insurance system and limited health finance is called for. It is emphasized for providing improved quality of care, to counter non-communicable diseases associated medical errors, and induced demand must be addressed within the health-care provision in Iran's health care domain. For financial risk protection measures alterations in health-care 
provision, integrating the family physician and home care facilities, better quality of care, and implementing national guidelines. ${ }^{16}$

\section{Psychiatric disorders and traumatic injuries in Iran:}

Psychiatric issues and injuries are bi-directionally associated. World-wide incident of deaths due to injury are $10 \%$. The Injury related disability-adjusted life years (DALY) have multiplied in the past 20 years and features among the leading attributes due to disability. Similarly, psychiatric disorders, and major public health problems, are linked with high disability rates. Importantly, unipolar depressive disorder is the largest reason of YLD and present increased DALY in $2030 .{ }^{40}$ In Iran, injuries ensued mental disorders are linked with highest disability rates through all age brackets and sexes, leading to $16 \%$ and $28 \%$ of DALY, respectively. Mental issues related to injuries, irrespective of the modus operandi of injury and the organ damaged, have been elucidated on a large scale. These issues are a result of anxiety disorders such as post-traumatic stress disorder (PTSD), mood issues due to major depressive disorder (MDD) and alcohol abuse. On the contrary, mal-adaptive coping mechanisms and psychopathology is the main reason in the people with a background of psychopathology. Mental illness also serves as a reason for higher rates of injuries. Children and adolescents also demonstrate these behaviors. Injured population reflected increased account of previous mental-illness. Traumatic brain injury (TBI) also seemed to be common among psychiatric patients. Cognitive impairment, decreased concentration and drowsiness due to medicines could be the reason for these aspects. Therefore, the association of injuries with mental and behavioral disorders in general public was evaluated. ${ }^{40}$

\section{Psychological features and drug use in Iran:}

The interlink between psychological features and drug abuse was longitudinally assessed, from preschool through 18 years of age. In the sample adolescents who tried out drugs mostly marijuana was the best-adjusted. Interpersonal estrangement, inadequate impulse control, and apparent emotional distress are the personality traits observed in adolescents who abused drugs more frequently relative those who had never tried drug. Early impression of a child is that of their interaction with their parents and this determines their psychological health and the variation between drug addicts, experimenters, and those who stay away from drugs. Unfortunately, today the psychological reason behind the abuse of drug is not catered too; rather it concentrates on the symptom. Evidence has it that drug abuse is only a symptom and not related to personal or social maladjustment, and an individual's personality trait and development is responsible for drug use. ${ }^{41}$ Deilamizade in 2015, Tehran study assessed drug abusers in Drop-In Centers $(n=23)$ and At Home Treatment facilities $(n=25)$. The outcomes indicate that when cost of drugs are high, cheaper drugs are opted for, which can play havoc with heath of a person, even mode of 
administration is harmful, which includes drugs injections, needles sharing, and money retrieved from illegal sources. Embargoes have painfully dwindled Iranian's economic standings since 2006 and intensified in 2010 and 2011. As an essential result of these economic embargoes, saw the increased costs of drugs, and other utility items. These embargoes have altered drug use trends, and intensified harm caused by drug abuse, can further estimated to rise in the future. ${ }^{42}$

\section{Suicide in Iran:}

The interrelation of demographic, social, and cultural factors has contributed to suicide in Iran and plays an essential public health issue. The global incidence of suicides was 804,000 as per the WHO, in 2012 alone. It is predicted that by 2020, 1.53 million individuals will succumb to suicide. Although, Islamic countries have a low preponderance of suicides but statistics have shown an upward trend lately. Iran, exhibited the suicide frequency to be 5.3 per 100000 individuals ( 3.6 in women, and 7.0 in men). Suicide is a direct consequence of domestic disputes (32\%), matrimonial issues (26\%), financial limitations (12\%), and academic fiasco (5\%). Various other factors attribute suicides for instance, genetic, mental illness, familial conflicts, politico- socio-economical conditions, and geographical-contribute to the risk of suicidal behaviour. Urban lifestyles bring added stress with higher suicide frequency in cities compared to rural areas. Drug use and self-immolation are usual modes of committing suicide in Iran. Life skills training and psychological support for youths, increasing household income, and pre-marriage counseling can help to reduce suicide rate. ${ }^{43}$

\section{Conclusion}

Although there is unanimity regarding the role of healthy population in sustained economic growth of a country; similarly, healthier population is also a result of economic growth. Any attempt to curb the economy through sanctions does not independently hamper the financial aspects; rather it has tremendous per capita impact which naturally extends to the overall physical and mental well being of the citizens in places where sanctions are imposed; not to mention the brazen disruption of human rights which is equivalent to war ridden countries. If countries executing sanctions against Iran have breached the Iranian citizen's right to health the repercussions should have been weighed beforehand and possibly averted. Not to ignore the responsibility of the targeted country in this case Iran to safeguard the interests and welfare beforehand of each and every individual dwelling there. Irreversible damage like disability and mortality cannot be worked on but pacifying negative impact of sanctions is a more pragmatic strategy. Embargoes have severe implications on indigenous population and calculated execution is expected.

\section{Acknowledgements}


The author of the article need to thank the cooperation and assistance of all the loved ones who helped us in this research.

\section{Conflict of interest}

The authors have no conflict of interest to declare.

\section{Funding}

This research did not receive any specific grant from funding agencies in the public, commercial, or not-for-profit sectors.

\section{References}

1. Kokabisaghi1 F. Assessment of the Effects of Economic Sanctions on Iranians' Right to Health by Using Human Rights Impact Assessment Tool: A Systematic Review, Int J Health Policy Manag. 2018; 7(5): 374-393.

2. Iran Nuclear Agreement. [https://fas.org/sgp/crs/nuke/R43333.pdf]. Accessed 1 Jun 2016.

3. International Sanctions on Iran. [http://www.cfr.org/iran/international-sanctions-iran/p20258]. Accessed 1 Jun 2016.

4. Iran Sanctions. [https://www.treasury.gov/resource-center/sanctions/programs/pages/iran.aspx]. Accessed 10 oct 2019.

5. Akbarpour N, Abbasi M. The Impact of the U.S. Economic Sanctions on Health in Cuba, October 2014, Available From: https://www.researchgate.net/publication/313116398

6. Six charts that show how hard US sanctions have hit Iran. [https://www.bbc.com > news > world-middle-east48119109]. Accessed 2019.

7. Dendrinou V, Chrysoloras N. EU, China, Russia Defy Trump With Plan to Keep Trading With Iran. [https://www.bloomberg.com/news/articles/2018-09-25/eu-defies-trump-with-plan-to-enable-continued-tradewith-iran]. Accessed 25 sep 2018.

8. Sadeghi S. For Many Iranians, Staying In the Nuclear Deal No Longer Makes Sense. [https://foreignpolicy.com/2019/09/24/for-many-iranians-staying-in-the-nuclear-deal-no-longer-makes-sense/]. Accessed 24 sep 2019

9. Setayesh S, Mackey T. K. Addressing the impact of economic sanctions on Iranian drug shortages in the joint comprehensive plan of action: promoting access to medicines and health diplomacy. Globalization and health. 2016; $12(1): 31$.

10. Kokabisaghi F. Assessment of the Effects of Economic Sanctions on Iranians' Right to Health by Using Human Rights Impact Assessment Tool: A Systematic Review. International Journal of Health Policy and Management. 2018; 7(5): 374-393.

11. Garfield R. The Impact of Economic Sanctions on Health and Well-being. Relief and Rehabilitation Network (RRN). London: Overseas Development Institute; 1999.

12. Hoskins E. Nutt S. The Humanitarian Impact of Economic Sanctions on Burundi. Occasional Paper 29, Watson, Institute for International Studies (Providence: Watson Institute); 1997.

13. Human Rights Watch, Cuba's Repressive Machinery: Human Rights Forty Years After the Revolution, 1 June 1999, 2343, available at: https://www.refworld.org/docid/3ae6a85f0.html [accessed 22 July 2019] 
14. Morin K, Miles S.H. The Health Effects of Economic Sanctions and Embargoes: The Role of Health Professionals. Ethics and Human Rights Committee. Annals of Internal Medicine. 2000; 132(2):158-61.

15. Noorbala AA, Faghihzadeh S, Kamali K, Bagheri Yazdi SA, Hajebi A, Mousavi MT, Akhondzadeh S, Faghihzadeh E, Nouri B. Mental health survey of the adult population of Iran in 2015. Arch Iran Med. 2017; $128-134$.

16. Danaei G, et al. Iran in transition, The Lancet. 2019; 393(10184): 1984-2005.

17. Ipser JC, Stein DJ. A systematic review of the quality and impact of anxiety disorder meta-analyses. Current psychiatry reports. 2009; 11: 302-309.

18. Aina Y, Susman JL. Understanding comorbidity with depression and anxiety disorders. J Am Osteopath Assoc. 2006; 106(5 Suppl 2): S9-14.

19. Naghavi M, Abolhassani F, Pourmalek F, Lakeh M, Jafari N, Vaseghi S, Mahdavi Hezaveh N, Kazemeini H. The burden of disease and injury in Iran 2003. Popul Health Metr. 2009; 7:9.

20. Mohammadi MR, Davidian H, Noorbala AA, Malekafzali H, Naghavi HR, Pouretemad HR, et al. An epidemiological survey of psychiatric disorders in Iran. Clin Pract Epidemiol Ment Health. 2005; 1:16.

21. Marmot M. The status syndrome: how social standing affects our health and longevity. New York: Owl Books; 2004.

22. Noorbala AA, Faghihzadeh S, Kamali K, Bagheri Yazdi SA, Hajebi A, Mousavi MT, Akhondzadeh S, Faghihzadeh E, Nouri B. Mental health survey of the adult population of Iran in 2015. Arch Iran Med. 2017; 20(3): $128-134$.

23. Hajebi A, Motevalian SA, Rahimi-Movaghar A, Sharifi V, Amin-Esmaeili M, Radgoodarzi R, Hefazi M. Major anxiety disorders in Iran: prevalence, sociodemographic correlates and service utilization, BMC Psychiatry. 2018; $18: 261$.

24. Kendler KS, Walters EE, Neale MC, Kessler RC, Heath AC, Eaves LJ. The structure of the genetic and environmental risk factors for six major psychiatric disorders in women. Phobia, generalized anxiety disorder, panic disorder, bulimia, major depression, and alcoholism. Arch Gen Psychiatry. 1995; 52(5): 374-83

25. Shear MK. Anxiety disorders in women: gender-related modulation of neurobiology and behavior. Semin Reprod Endocrinol. 1997; 15(1): 69-76.

26. Redmond G. Mood disorders in the female patient. Int J Fertil Womens Med. 1997; 42(2): 67-72.

27. Butler T, Pan H, Epstein J, Protopopescu X, Tuescher O, Goldstein M, et al. Fear-related activity in subgenual anterior cingulate differs between men and women. Neuroreport. 2005; 16(11): 1233-6.

28. World Health Organization. Closing the gap: policy into practice on social determinants of health: discussion paper. Rio de Janeiro: WHO; 2011.

29. Luke A. Critical literacy: foundational notes. Theory Pract. 2012; 51(1): 4-11.

30. Lincoln A, Espejo D, Johnson P, Paasche-Orlow M, Speckman JL, Webber TL, White RF. Limited literacy and psychiatric disorders among users of an urban safety-net hospital's mental health outpatient clinic. J Nerv Ment Dis. 2008; 196(9): 687-93. 
31. Vijayalakshmi P. Ramachandra, Reddemma K, math SB. Perceived human rights violation in persons with mental illness: role of education. Int J Soc Psychiatry. 2013; 59(4):351-64.

32. Lincoln A, Paasche-Orlow MK, Cheng DM, Lloyd-Travaglini C, Caruso C, Saitz R, Samet JH. Impact of health literacy on depressive symptoms and mental health-related: quality of life among adults with addiction. $\mathbf{J}$ Gen Intern Med. 2006; 21(8): 818-822.

33. Zhang S, Bhavsar V. Unemployment as a risk factor for mental illness: combining social and psychiatric literature. Adv Appl Sociol. 2013; 3(2): 131-136.

34. Paul KI, Moser K. Unemployment impairs mental health: meta-analysis. J Vocat Behav 2009; 74: $264-282$.

35. Haller H, Cramer H, Lauche R, Gass F, Dobos GJ.The prevalence and burden of subthreshold generalized anxiety disorder: a systematic review. BMC Psychiatry. 2014; 14: 128.

36. Zarafshan H, Mohammadi M, Salmanian M, Prevalence of Anxiety Disorders among Children and Adolescents in Iran: A Systematic Review. Iranian Journal of Psychiatry. 2015; 10(1): 1-7.

37. Katschnig H .Quality of life in mental disorders: challenges for research and clinical practice. World Psychiatry. 2006; 5(3): 139-145.

38. Connell J, Brazier J, O’Cathain A, Lloyd-Jones M and Paisley S. Quality of life of people with mental health problems: a synthesis of qualitative research. Health and Quality of Life Outcomes. 2012; 10:138.

39. Datta P.P, Gangopadhyay N, Sengupta B. Association of Psychological Morbidity with Socio-Demographic Characteristics among Elderly: A Cross-Sectional Study from Eastern India, International Journal of Medicine and Public Health. 2013; 3(2):94-99.

40. Shadloo B, et al. Psychiatric Disorders Are Associated With an Increased Risk Of Injuries: Data From The Iranian Mental Health Survey (Iranmhs). Iran J Public Health. 2016; 45(5): 623-635.

41. Shedler J, Block J. Adolescent drug use and psychological health: A longitudinal inquiry. American Psychologist. 1990; 45(5): 612-630.

42. Deilamizade A, Esmizade S. Economic Sanctions against Iran, And Drug Use In Tehran, Iran: A 2013 Pilot Study. Substance Use \& Misuse. 2015; 50(7):1-10.

43. Mirhashemi S, Motamedi A.H, Taghipour H, Danialet Z. Suicide in Iran. The Lancet. 2016; 387(10013): 29. 